\title{
Distribution and ignorance
}

\section{Juha Räikkä ${ }^{1}$}

Received: 26 November 2018 / Accepted: 29 April 2019 / Published online: 10 May 2019

(c) The Author(s) 2019

\begin{abstract}
According to the so-called presumption of equality, a person who does not know whether there is an acceptable reason for differential treatment should just presume the similarity of the cases and treat them equally. If we assume that the presumption of equality is an acceptable moral principle, at least when the allocation cannot be postponed and an equal distribution of goods is possible, then an important question arises: when exactly does the allocator have sufficient reasons for differential treatment and is not relevantly ignorant? This is a question about the required strength of the "acceptable reasons" for differential treatment. It has been commonplace to think that the presumption of equality demands that the reasons that refute the presumption must be very strong and that differential treatment requires that there is a proper justification for the claim that the cases are relevantly different. I will argue, however, that refuting the presumption and solving the issue (of whether the cases are relevantly similar or relevantly different) are two separate matters. A person can have good enough reasons for rejecting the presumption that the cases are relevantly similar without having reasons that she could present as a full justification for the claim that the cases are relevantly different. A precondition of the applicability of the presumption of equality is ignorance, but not ignorance in the sense of "not having a full justification".
\end{abstract}

Keywords Ignorance · Presumption of equality · Justice · Justification ·

Burden of proof

\section{Introduction}

According to the formal principle of distributive justice, similar cases should be treated similarly and different cases differently. We can tell which cases are relevantly similar and which are relevantly different if we have a substantive criterion of justice and sufficient information about the cases. A person has an acceptable reason to treat

Juha Räikkä

jraikka@utu.fi

1 Department of Philosophy, University of Turku, Assistentinkatu 7, 20014 Turku, Finland 
cases differently if she has an acceptable reason to think that the cases are different according to an appropriate criterion. ${ }^{1}$ Suppose, however, that a person does not have such a reason-that she does not know whether there is an acceptable reason for differential treatment. According to the so-called presumption of equality, she should then treat cases equally and just presume the similarity of the cases, that is, if she does not know it. ${ }^{2}$ A precondition of the applicability of the presumption of equality is ignorance. ${ }^{3}$ The burden of proof is on the side of a person who plans to treat cases differently; to meet the requisite burden of proof is to "show" that one is not ignorant. 4 Having an acceptable reason for differential treatment refutes the presumption that the cases are relevantly similar.

The presumption of equality is a controversial guide for decision-making. Many authors have defended the presumption of equality but critics have argued that the principle is morally questionable. ${ }^{5}$ Why should we distribute, say, student grants equally, if we do not have any information about their respective merits? If we assume that the presumption of equality can be an appropriate moral principle, at least when the allocation cannot be postponed and an equal distribution of goods is possible, then an important question arises: when exactly has the allocator met the alleged burden of proof and is not relevantly ignorant? When does the allocator have sufficient reasons for differential treatment? This is a question about the required strength of the "acceptable reasons" for differential treatment and an unequal distribution of goods. Although the issue is a matter of degree, the literature concerning the presumption of equality suggests that there are two main options. Either (1) the standard of proof is relatively low and an allocator is not ignorant if she is not at a loss and can make the distribution in a sensible way, or (2) the standard used as a burden of proof is very high and an allocator is ignorant until she can impartially and rationally justify the claim that the cases are relevantly different. ${ }^{6}$ Roughly speaking, to borrow the terminology from jurisprudence, the first account is based on the idea that it suffices that "reasonable indications" support the claim that the cases are different, while the

\footnotetext{
1 In what follows, I will assume that when a person has "an acceptable reason for differential treatment" it means that she cannot also have an acceptable reason for equal treatment. Of course, a person can have all kinds of reasons for and against differential (and equal) treatment.

2 Graham (1965, p. 64). "Absence of grounds for discriminating obliges one to treat equally."

3 Cf. Feinberg (1973, p. 101) and Browne (1975, p. 52).

4 Benn (1967, p. 40). The "onus of proof rests on whoever wants to make distinctions".

5 The supporters of the presumption of equality include Berlin (1955), Benn and Peters (1959), Frankena (1966), Rees (1971), Dixon (1986), Miller (1997), Rabinowicz (2008) and Gosepath (2015).

6 Westen (1990,pp. 241-242) argues that the supporters of the presumption of equality tend to think that the reasons "that suffice to rebut the presumption of equality" must be "moral reasons" (as opposed to amoral reasons) but not "morally right" reasons (that would justify the claim that the cases are different). I have a different impression. The motivation to support the presumption of equality is usually the conviction that the presumption can further social equality. The view that practically any "moral reason" suffices to rebut the presumption would not further social equality at all. A person can defend all kinds of morally questionable and strongly unequal goals, including racism and sexism, by reasons that are formally speaking "moral reasons" (as opposed to reasons that refer to one's personal preferences or something like that). Westen confesses that some philosophers (e.g. Cauthen 1987) have demanded that the reasons that can rebut the presumption of equality must be very strong. In my view it is possible that these philosophers form a majority. The presumption of equality "directs our attention towards the justification of inequalities rather than to their abolition. The emphasis is significant" (Dixon 1986, p. 51).
} 
second account says that it must be "beyond reasonable doubt" that the cases are relevantly different. ${ }^{7}$ On the second account, an allocator has an acceptable reason for differential treatment only if there is a strong or a "full" justification for the claim that the cases are relevantly different.

In what follows, I will first argue that an allocator should distribute goods equally if she does not have practically any information about the relevant features of the cases or the distributive criterion that should be used. In such circumstances (when a person is at a loss) the presumption of equality looks as though it is a rather plausible principle, or so I argue. I will then turn to the interpretation of the presumption of equality that demands that the reasons that refute the presumption must be very strong and that differential treatment requires that there is a proper justification for the claim that the cases are relevantly different. This claim-the justificational view-has been a popular interpretation of the presumption of equality, and I aim to show that so interpreted the presumption is not plausible. The justificational view assumes that the presumption of equality can be refuted only by deciding whether the cases actually are similar or different, but I will argue that refuting the presumption and solving the issue are two separate matters. A person can have good enough reasons for rejecting the presumption that the cases are relevantly similar without having reasons that she could present as a full justification for the claim that the cases are relevantly different. That is, it is possible that a person has reasons that refute the presumption in favor of equal treatment — and that she is not ignorant in that respect-even if she does not know whether the cases actually are similar or different.

My aim here is not to defend the view that the standard of proof should be relatively low. The aim is only to criticize the view that the standard of proof should be very high. As far as the problems I will mention are real, they should show that the presumption of equality can be justifiably applied much less often than its supporters tend to think.

The limited applicability may have political implications, depending on the context. It is not the case that we should always presume similarity and support equal distribution when we lack waterproof evidence about the difference of the cases. Unequal distribution can be acceptable even when the arguments in favor of it do not meet the most demanding standards. This result shows the importance and relevance of the present discussion.

\section{Ignorance as being at a loss}

Let us start with a general defense of the presumption of equality by replying to an objection that has been rather common. According to the traditional criticism of the presumption of equality, the presumption in favor of equal distribution is arbitrary. This objection is not addressed against any particular interpretation of the presumption of equality; the objection criticizes the presumption of equality in general. According to critics, the proponents of the presumption of equality commit a logical fallacy,

\footnotetext{
7 When "balance of probabilities" supports the claim that the cases are different then it is "more probable than not" that the claim is true. The question is of the "preponderance of the evidence" standard.
} 
that is, the ad ignorantiam fallacy. ${ }^{8}$ In the critics' view, the proponents think that the proposition that there is no reason to treat the cases differently entails the proposition that there is a reason to treat them equally. ${ }^{9}$ But obviously this is not so. "Not having a normative reason for treating people unequally is not the same as having a normative reason for treating them equally for it is possible that one may have no normative reasons for treating them either one way or the other". ${ }^{10}$

The traditional criticism against the presumption of equality is often based on the assumption that the basis of presumptions must be inductive. The claim is that when there are no inductive grounds for presuming, one should not make a presumption in the first place. ${ }^{11} \mathrm{D}$. E. Browne links presumptions to induction and suggests that the proper response to ignorance is simply inaction.

It is easy now to see what we should say about the situation in which our knowledge of $A$ and $B$ and of their circumstances is so meagre that there is no inductive warrant for presuming either that they will probably deserve equal treatment, or that they will probably deserve unequal treatment. We should say, not that there is an a priori principle which demands of us that we should presume equality, but that the only reasonable thing to do is not to presume at all. It is true that there is no reason for treating $A$ and $B$ differently. It is also true that there is no reason for treating $\mathrm{A}$ and $\mathrm{B}$ the same. What is not true is that the proposition that there is no reason for treating them differently entails the proposition that there is a reason for not treating them differently. ${ }^{12}$

Richard Norman agrees that if there is no reason to believe that the cases are relevantly similar, or a reason to believe that it is likely that they are relevantly similar, then there cannot be a reason for presuming their similarity either. According to this view, reasons for believing are not distinguishable from reasons for presuming.

Now it may be true, in some general sense, that inequalities are arbitrary if no reason can be given for them. However, it does not follow that equality is then any less arbitrary. All that follows is that, in the absence of reasons, any pattern of distribution, equal or unequal, is arbitrary. In other words, it does not matter what pattern of distribution is adopted. Equality is just as arbitrary as inequality, unless some positive reason can be given for it. I do not see how, in the absence of such reasons, there can be any positive "presumption of equality". 13

The traditional criticism is, however, problematic. It overlooks that fact that presumptions are, primarily, pragmatic tools that should help decision-makers, and that their basis is rarely inductive (although it can be). ${ }^{14}$ When a person must make at least some

\footnotetext{
8 For a discussion, see Walton (1988) and Walton (1996).

9 See e.g. Browne (1975, p. 52).

10 Westen (1990, p. 242).

11 Relying on a presumption can be rational and helpful even when the agent is relatively certain about relevant matters. Räikkä (2014, p. 54). It is often said that presumptions are needed especially "in the absence of knowledge". Walton (1996, p. 211).

12 Browne (1975, p. 52).

13 Norman (1987, pp. 57-58).

14 According Ullmann-Margalit (1983), inductive presumptions are not real presumptions.
} 
decision, presumptions can help her. In many cases the use of a presumption is clearly a better option than the use of, say, a lottery. ${ }^{15}$ A person who does not know whether an old bridge in a nature trail will support her may presume that it will not support her and seek another path to continue. Her presumption is reasonable, even if it is not based on any evidence about the (bad) condition of the bridge or on considerations about the reliability of bridges in general. The presumption guides her to act in a way that cannot lead to a serious accident (although it means that she should take a slightly longer route). The person seems to follow the principle that one should "err on the side of safety". ${ }^{16}$ She can refute the presumption if she suddenly finds out that the bridge is quite safe, for instance, by observing that a group of people just crossed it without incident.

The presumption of equality can be justified in a similar fashion, and it shows that the presumption need not have an "arbitrary character". ${ }^{17}$ Reliance on the presumption of equality is reasonable when an allocator is at a loss how to make a distribution between the cases. For simplicity, suppose that a wealthy person hires two builders (A and B) to restore her summer house. They agree that (because of reasons related to taxation) the payment will be two paintings that will be distributed among the builders on the basis of their "efficiency". Unfortunately, after the job, she does not have a clue how efficient the workers were in comparison to each other. She talks about the issue with the workers and with a group of other people but cannot form a coherent picture of the situation. Since she cannot postpone the allocation, she decides to make equal distribution and gives one painting to each worker. She understands that presuming that the workers were equally efficient prevents the worst possible distribution, namely, the distribution in which the person who should not get anything gets everything and the person who should get everything gets nothing. ${ }^{18}$ Reliance on the presumption of equality will "minimize the expected injustice" 19 and "the expected unfairness of the outcome." 20 Given that the allocator's ignorance is not her own fault-that she is non-culpably ignorant-she is justified to give each worker one painting. ${ }^{21}$ An equal distribution guarantees that the worst that can happen is that one worker has one painting too many and the other lacks one painting that belongs to her. (Of course, the allocator is free to give two paintings for both workers if she happens to have them.)

Notice that a person can consciously rely on the presumption of equality only if she realizes that she is, in the relevant sense, ignorant. Successful application of the presumption of equality requires knowledge about one's ignorance. The demand that a relevantly ignorant person ought to rely on the presumption of equality fits well in

\footnotetext{
15 The presumption of equality can be defended by referring to determinateness considerations. To presume equality gives definite guidance for the allocator whereas the alternative presumption, the presumption of inequality, would be rather indefinite, as there are numerous ways to distribute goods unequally. UllmannMargalit (1983, p. 161) and Räikkä (2014, p. 55).

16 Walton (1996, p. 210).

17 Feinberg (1973, p. 101).

18 Räikkä (2018, p. 1).

19 Miller (1997, p. 228).

20 Rabinowicz (2008, p. 109). Cf. Rabinowicz (2011).

21 Arguably, "an agent ought to perform an act if and only if the option minimizes the maximum possible loss of value" (Smith 2010, p. 5).
} 
those situations in which a person has no idea whether the cases are similar or different. In those situations an allocator will probably realize immediately that she lacks the relevant information, and the requirement that she should use the presumption is therefore reasonable. The requirement is not too demanding when "being ignorant" means "being at a loss". 22 (Here "being ignorant" does not mean "lacking justification".)

In the example above, the allocator of the paintings does not know the relevant facts (concerning the efficiency of the workers), but she does know the criterion that should be used in the distribution. Is the presumption of equality a plausible principle in circumstances where an allocator is at a loss because she does not have any idea what should be the correct criterion of distribution? Peter Westen has argued that the presumption of equality is meant especially for such circumstances (where we are normatively uncertain). In his view, the "object of the presumption of equality, then, is to help an actor decide which rule to adopt when he is normatively uncertain about whether to treat certain people equally or unequally" and it "does so by instructing him provisionally to adopt rules that treat people equally rather than unequally - that is, rules that refrain from distinguishing among persons of a particular class as opposed to rules that do distinguish among them". ${ }^{23}$

Suppose that if an allocator uses "need" as a distribution criterion, then the goods will be distributed equally between the cases (such as two workers), but if she uses "diligence" as a criterion, then the goods (such as two paintings) will be distributed unequally. The claim that the allocator should prefer the "need" criterion to the "diligence" criterion does not look plausible if these two criteria are the only options she has. The error costs of the options are equal. If "need" is the correct criterion while "diligence" is used as the criterion, then the other worker gets one painting too many and the other worker one too few. ${ }^{24}$ But the situation is the same if the correct criterion is "diligence" while "need" is used as the distribution criterion (and the paintings are distributed equally). Again, the result is that the other worker gets one painting too many and the other worker one too few.

\begin{tabular}{lll}
\hline & Worker 1 & Worker 2 \\
\hline Need & 1 painting & 1 painting \\
Diligence & 2 paintings & 0 paintings \\
\hline
\end{tabular}

However, the situation changes if the allocator has more options and the criteria point to different directions and thus give completely conflicting guidance. In such circumstances the presumption of equality is reasonable if the allocator is "normatively uncertain". In the following situation, a responsible (but ignorant) allocator would use the "need" criterion, as it would prevent the worst possible distribution, namely, the

\footnotetext{
22 "Being ignorant" has various meanings, "being at a loss" and "lacking full justification" being just two of them.

23 Westen (1990, p. 249). Westen does not directly support the presumption of equality. Notice that "being at a loss" is only one meaning of "being ignorant".

24 The distributive criterion can be said to be "correct" for many reasons; for instance, if the relevant parties have freely agreed that it will be used as a criterion.
} 
distribution in which the person who should not get anything gets everything and the person who should get everything gets nothing.

\begin{tabular}{lll}
\hline & Worker 1 & Worker 2 \\
\hline Effort & 0 paintings & 2 paintings \\
Need & 1 painting & 1 painting \\
Diligence & 2 paintings & 0 paintings \\
\hline
\end{tabular}

Now, people are often uncertain which criteria they should use when they distribute goods (say, student grants, or legal entitlements to refugees and migrants). When they notice that many criteria are plausible but that they provide conflicting guidance, then they may decide to make an equal distribution (given that there are sufficient resources for that solution). But this decision is hardly based on the presumption of equality. It is more likely that the decision to make an equal distribution is based on a view that using many criteria at the same time is justified and when many criteria are used at the same time then the cases are relevantly equal and should therefore be treated equally. No presumption is needed. Alternatively, in some situations when the distributive criteria are mixed, goods are probably distributed equally merely in order to avoid strong reactions. This solution can be reasonable, although it has little to do with justice.

The presumption of equality is a plausible principle in some circumstances, in particular, when the allocator is at a loss how to make the distribution because she does not know the relevant facts about the cases or is just unable to choose between the distributive criteria that point to many different directions.

\section{Ignorance as a lack of justification}

The important question is, exactly when and under what circumstances is an allocator justified in rejecting the presumption of equality. What is the required strength of the acceptable reasons for differential treatment? Possibly, the reasons need not be particularly deep and convincing - otherwise there is a risk that the burden will rarely be met $^{25}$ — but this view has not been the only stance on the debate. According to the justificational interpretation of the presumption of equality, the reasons that refute the presumption must be very strong, so that the allocator can clearly justify the claim that the cases are different. It does not suffice that justifying reasons "seem sufficient to the discriminator". ${ }^{26}$ If the allocator cannot justify the claim that the cases are different, she is relevantly ignorant and under the obligation to follow the guidance of the presumption of equality.

The justificational interpretation consists of two parts. The first part states the basic idea of the presumption of equality, saying that the burden of proof is on the side of a discriminator. The second part claims that meeting the burden requires justification that shows the relevant difference between the cases.

\footnotetext{
25 Cf. Westen (1990, p. 242).

${ }^{26}$ Rees (1971, p. 131).
} 
The first part was supported by Isaiah Berlin already in the 1950s. He argued that "equality needs no reasons, only inequality does so". ${ }^{27}$ Berlin writes that if "I have a cake and there are ten persons among whom I wish to divide it, then if I give exactly one tenth to each, this will not, at any rate automatically, call for justification; whereas if I depart from this principle of equal division I am expected to produce a special reason". ${ }^{28}$ Stanley Benn and Richard Peters made a similar point. They argued that

the principle of equality does not prescribe positively that all human beings be treated alike; it is a presumption against treating them differently, in any respect, until grounds for distinction have been shown. It does not assume, therefore, a quality which all men have to the same degree, which is the ground of the presumption, for to say that there is a presumption means that no grounds need be shewn. The onus of justification rests on whoever would make distinctions. ${ }^{29}$

R. M. Hare defended the view that unequal treatment requires that a difference between the cases is known, for "otherwise we are making different moral judgments about similar cases". ${ }^{30}$ William K. Frankena formulated the presumption of equality as the principle that one should treat "people equally unless and until there is a justification for treating them unequally". ${ }^{31}$ More recently, Stefan Gosepath has argued for the view that the "burden of proof lies with the one who seeks to justify an unequal treatment". 32 "Unequal distribution requires justification, equal distribution does not" 33 Gosepath's example originates from Berlin, but (as opposed to Berlin) he argues that the burden of proof does not concern only the allocator but also others (and perhaps especially others) who defend an unequal distribution of goods. In Gosepath's view, "a parent who wishes to share a cake among his or her children" should divide it "into equally large pieces", given that "all children would like their slice to be as large as possible" and that "no child can advance a convincing reason why his or her slice should be larger than everyone else's". 34

A talk about presumptions is closely related to issues of burden of proof, and issues of burden of proof are in turn closely related to the notion of showing. When there is a burden of proof on one side in an argument, this means that the other side will be believed until something has been shown, either by actually presenting a reason that refutes the presumption or by having a reason that refutes the presumption. ${ }^{35}$

\footnotetext{
27 Berlin (1955, p. 305).

28 Berlin (1955, p. 305).

29 Benn and Peters (1959, pp. 127-128).

30 Hare (1963, p. 119).

31 Frankena (1966, p. 8).

32 Gosepath (2015, p. 177). "Every sort of public, political distribution is, in this view, to be justified to all relevantly concerned persons, such that they could in principle agree." Gosepath (2007, Chapter 2.4).

33 Gosepath (2008, p. 207).

34 Gosepath (2015, p. 177).

35 Katzner (1970, p. 255). See also Katzner (1973, p. 92). In his discussion of the presumption of equality, Katzner (1970, p. 255) writes that "the notion of a 'presumption' involves establishing a 'burden of proof'. The real force of establishing a 'burden of proof' is to make the point at issue primarily one of 'showing'. When there is a burden of proof on one side in an argument, this means that the other side will be believed
} 
The second part of the justificational interpretation of the presumption of equality says that the "something" that should be shown is that the presumption that the cases are relevantly similar is not justified. To show it, one must present or at least have a justification for the claim that the cases are relevantly different. If and only if she has such a justification, she has an "acceptable and sufficient reason" for the rejection of the presumption and thus for the differential treatment of the cases.

The idea that "to be ignorant" means "lacking a justification" has been common in the literature. The usual assumption has been that the refutation of the presumption of equality can happen only by considering whether the cases actually are similar or different, and that the reasons that are a strong enough to refute the presumption must be reasons that provide a proper or a full justification for the claim that the cases are relevantly different. John Rees argues that the presumption of equality "requires of any would-be discriminator to show what it is about any person or group of persons that would justify their exclusion" from equal treatment. ${ }^{36}$ Keith Dixon writes that the presumption of equality "places the burden of justification squarely upon the shoulders of those who wish to discriminate" and that differential treatment should be "rationally justified" by "rigorous argumentation and by sound empirical evidence". 37 Stefan Gosepath has argued in a number of papers that to refute the presumption of equality is to justify the claim that the cases are relevantly different. In his view, "it is morally necessary to justify impartially any unequal distribution". ${ }^{38}$ An unequal distribution should be "justified to all relevantly concerned persons, such that they could in principle agree". ${ }^{39}$ Differential treatment should be "universally and reciprocally justified to all", otherwise an "equal distribution is the only legitimate principle of distribution". 40 Anyone "who lays claim to more than an equal share owes all others an adequate universal and reciprocal justification". ${ }^{41}$ According to Gosepath, the relevant reference point is that of criminal law. ${ }^{42}$ In criminal proceedings, the accused need not "prove his innocence but the state must prove his guilt. The same goes for the presumption of equality."43

Many supporters of the justificational interpretation of the presumption of equality argue not only that would-be discriminators should have justifying reasons but also that they should present them. ${ }^{44}$ The demand that an allocator should present her reasons for the relevant persons involved is reasonable in the sense that this might

Footnote 35 continued

until it can be shown to be wrong; and hence which side is actually right is in a sense a question of secondary importance."

36 Rees (1971, p. 137). See also Rees (1971, p. 131).

37 Dixon (1986, p. 51).

38 Gosepath (2007, Chapter 2.4).

39 Gosepath (2007, Chapter 2.4). The claim that the reasons that are supposed to justify differential treatment should be "generally acceptable" is very demanding. For a discussion, see Bohman and Richardson (2009).

40 Gosepath (2015, pp. 182-183).

41 Gosepath (2015, p. 182).

42 "We find a similar presumption in criminal proceedings" (Gosepath 2008, p. 207).

43 Gosepath (2008, p. 208).

44 Norman (1987, p. 57) criticizes the presumption of equality but he argues that the presumption assumes that the "onus is on the advocate of inequality, rather than the advocate of equality, to supply reasons". Italics added. 
help her to notice whether there is something wrong with the reasons she has in mind. However, it is one thing to require that, (1) in the absence of relevant information, an allocator distributes goods equally, and another thing to require that (2) an allocator offers reasons for her decision in public. The second demand is not directly related to our concern here (which is the question how strong reasons suffice to rebut the presumption of equality).

For the present purposes it suffices to say that, as such, the second demand is plausible, but only in some circumstances. Surely a person should explain why she treats people differently when many expected similar treatment. But the moral duty to explain the grounds of one's decisions is a separate matter which is not directly linked to the presumption of equality. Even a person who opposes the presumption of equality can support the claim that it is often polite and morally appropriate to tell others what the reasons behind the decision which leads to inequalities are. However, it seems clear that we need not always present reasons for public scrutiny. A duty to present reasons is relevant when the distribution is unequal but "individuals involved are believed, assumed, or expected to be equal in the relevant respects", as argued by Joel Feinberg. ${ }^{45}$ In other cases it is not necessary to provide long (or even short) justifications for one's decisions. If the winner of a running competition gets the first prize but others do not, there is no need for the presentation of justifying reasons. This is in line with the rather ordinary view that "people have a burden to present some reasons when they make accusations or statements that run counter to common opinion", but not at other times. ${ }^{46}$ We can safely put the second demand aside.

To summarize, there is a long tradition that suggests that an allocator ought to distribute goods equally if she is relevantly ignorant, and that she is relevantly ignorant if she lacks an explicit and sufficient justification for the claim that the cases are relevantly different. ${ }^{47}$ The justificational view assumes that the presumption of equality can be refuted only by considering whether the cases really are similar or different. The assumption is that only such reasons that form a full justification for the claim that the cases are relevantly different are strong enough to refute the presumption that the cases are relevantly similar. Next, I will criticize that assumption. ${ }^{48}$

\section{A problem of the justificational view}

The justificational interpretation of the presumption of equality consists of two claims. The first claim is that an allocator is not relevantly ignorant if she has a proper justifi-

\footnotetext{
45 Feinberg (1973, p. 101).

46 Fogelin and Sinnott-Armstrong (1991, p. 319).

47 It is not clear that a person who believes the truth but without justification is really ignorant of the truth. Arguably she is not. See Zimmerman (1997, p. 412) and Peels (2010, pp. 59-60). We can distinguish between "ignorance as lack of knowledge" and "ignorance as lack of true belief". See Guerro (2017, p. 181). 48 The justificational interpretation of the presumption of equality can be criticized in many ways. For instance, one can object that the justificational view implies that an allocator should distribute goods equally even if all persons involved agree that goods should be distributed unequally but they do not happen to have a justification for their shared view. Surely this is a counter-intuitive implication. However, a supporter of the justificational view could say that the existence of agreement is the justification they need, and that therefore unequal distribution would be acceptable in the case described.
} 
cation for the claim that the cases are relevantly different. The second claim is that an allocator is relevantly ignorant if she does not have a proper justification for the claim that the cases are relevantly different. The first claim is obviously correct. A person who knows that the cases are different is not ignorant and therefore she is free (and even obligated) to treat cases differently. The second claim, however, is problematic. It can be argued that a person who cannot provide a full justification for the claim that the cases are relevantly different can still have reasons that are good enough to entitle her to reject the presumption that the cases are relevantly similar. Whether this is so depends on how much moral weight we attribute to the importance of (1) avoiding the worst possible distribution (in which the person who should not get anything gets everything and the person who should get everything gets nothing) and (2) avoiding the situation in which equal cases are treated unequally.

Suppose again that a person should allocate two paintings among two workers, A and B. She does not explicitly agree with the workers what will be the distribution criterion, but she decides to use a combination of criteria that are commonly used and certainly familiar to the workers (diligence, efficiency and so on). Unfortunately, after the job is completed she does not have a clue how well the workers did in comparison to each other. (She is not responsible for her ignorance.) However, she talks about the issue with a group of people who saw what happened, and someone who saw the job tells her that A did everything and B did nothing. Someone else adds that he also saw that A worked very hard. The allocator does not start to investigate the reliability and backgrounds of the persons who informed her but concludes that, probably, now justice can be done. She gives both paintings to A. There is no time for further considerations and the distribution cannot be postponed.

In this situation, we can say that it is very likely that the allocator made a correct decision. However, we cannot say that she had a full justification for her assumption that A deserves both paintings. It is certainly not "beyond reasonable doubt" that A does not deserve them both. First, it is possible that the mixed distributive criterion she used was not acceptable. The fact that the criterion was conventional does not prove much, and perhaps it was not implicitly accepted by the workers-although it is likely that it was. ${ }^{49}$ Second, it is possible that she had facts wrong. Her empirical thoughts about the difference between A and B were based merely on testimony. Although this is how we normally acquire our beliefs and are probably justified in doing so, it is still conceivable that, after all, A did not do everything. ${ }^{50}$ Let us stipulate that, in terms of likelihood, the situation is the following.

\footnotetext{
49 For a discussion on conventional standards of justice, see Rosen (2003). "According to one plausible standard, one is normally under no obligation to rethink the uncontroversial normative principles that form the framework for social life." But still these principles can be unacceptable and clearly wrong (Rosen 2003, pp. 65-66). An example is slavery that was once considered acceptable.

50 Testimony leads to the acquisition of knowledge in some circumstances but not in all circumstances. Social epistemologists encourage us to ask when testimony suffices for the acquisition of knowledge. No doubt, almost everything we know depends in some way or other on the testimony of others (cf. Lehrer 2006, p. 145; Foley 2001, p. 24; Adler 2002, p. 136; Lackey 2011, p. 71).
} 
Likelihood in the light of available reasons

$\begin{array}{lr}\text { A deserves } 2 \text { paintings } & 85 \% \\ \text { A and B both deserve 1 painting } & 10 \% \\ \text { B deserves 2 paintings } & 5 \%\end{array}$

Is the person's decision acceptable and correct from the point of view of justice when she gives both paintings to A? If it is, then it seems that the justificational interpretation of the presumption of equality is not acceptable, as there are cases in which a person is not relevantly ignorant and is justified to make unequal distribution even if she does not have a full justification for the claim that the cases are relevantly different. (One might say that she has only an empirically based presumption that the cases are relevantly different.)

I assume that most of us would say that the person's decision is reasonable from a point of view of justice. ${ }^{51}$ This is because most of us (probably) think that the expected value is highest when A is given two paintings. In our consideration, we take into account not only the gravity of the error but also the likelihood of the error. ${ }^{52}$ Since it is likely that A deserves both paintings, it is reasonable to give them to her, although it is possible that this leads to the worst possible distribution. Furthermore, it may happen that giving both paintings to A leads to the situation in which equal cases are treated unequally. These are serious costs, but their likelihood is so low that they should not prevent the decision to give both paintings to A and nothing to B. An ethical and morally responsible allocator relies on a "prospective view" and chooses the option that has the best prospects, so to speak..$^{53}$

Now, a supporter of the justificational view could deny that the allocator made an acceptable and reasonable decision. The supporter could mention that there are cases in which it may seem that a person's decision is unreasonable, but when her values are taken into account, it will turn out that the decision is rather reasonable, after all. Suppose that a person has to post a letter before the evening. The nearest post office is very likely to be open — she heard that it is open from various sources—but the post

\footnotetext{
${ }^{51}$ It is more likely than not that A did everything. The preponderance of evidence standard of proof has been met.

52 As Westen (1990, p. 249) writes, "presumptions generally rest on the relative risks of error in choosing between two alternatives, $\mathrm{P}$ and $\mathrm{Q}$. Presumptions in favor of $\mathrm{P}$ are justified whenever the risk of erroneously choosing $\mathrm{P}$ is less than the risk of erroneously choosing $\mathrm{Q}$. Two factors combine to constitute relative risks of error: the relative probabilities of error and the relative gravities of error. When there is a relatively lower probability of error in choosing $\mathrm{P}$ over $\mathrm{Q}$, there is a greater justification for presuming in favor of $\mathrm{P}$; when there is relatively lesser harm in erroneously choosing $\mathrm{P}$ over $\mathrm{Q}$, there is a greater justification for presuming in favor of P.".

53 Zimmerman (2008, pp. ix-x) writes: "John is suffering from a minor but not trivial skin complaint. Jill has three drugs with which she might treat him: A, B and C. All the evidence at her disposal indicates, in keeping with what is in fact the case, that giving John drug B would cure him partially and that giving him no drug would leave him permanently incurable; it also indicates that one of drugs A and C would cure him completely while the other would kill him, but it leaves completely open which of them would cure and which kill. What ought Jill to do? You are supposed to answer: 'She ought to give him drug B.' Jackson says that this answer is obvious, and I think he's right." According to Zimmerman, Jill's decision is obviously correct, as it has the best prospects. (My point is not to support Zimmerman's theory about the "prospective view", but my argument seems compatible with it.). See also Zimmerman (2014).
} 
office that is located further away is certainly open. Because of time limits the person cannot go to both offices. She decides to go to the one that is further away. When she is asked why she goes that office, she replies that it is extremely important that she posts the letter today, and that she does not want to take the risk of it not being collected-although her decision will cause her the inconvenience of traveling. ${ }^{54}$ The supporter of the justificational interpretation of the presumption of equality could say that the allocator of the paintings is, in some important respects, in a similar situation. The allocator should think that it is most important to prevent a situation in which (1) the worst possible distribution comes true or (2) equal cases are treated unequally. Therefore it is not reasonable for her to give both paintings to A (and likelihoods do not change the situation). Giving two paintings to $\mathrm{A}$ is the action she should avoid in particular. ${ }^{55}$ Her choice situation is the following:

The moral importance of avoiding

Unequals are treated equally

Moderately important

Equals are treated unequally or the worst possible distribution

Extremely important comes true

The claim that the allocator should not give both paintings to A despite the fact that it is quite clear that A deserves both of them, raises two questions. The first question is, why would it be more important not to treat similar cases differently rather than not to treat different cases similarly. Aren't they equally bad actions? The second question is, why should the allocator think (as the supporter of justificational view could say) that it is most important to avoid the situation in which either the worst possible distribution comes true or equal cases are treated unequally. Isn't it most important to make the prospectively best decision?

Let us start with the first question. The idea that it is more important not to treat similar cases differently than not to treat different cases similarly has been defended by referring to rather pragmatic reasons. It has been pointed out that, in institutional contexts, (1) people tend to avoid more systematically situations in which relevantly similar cases can be treated differently from situations in which relevantly different cases can be treated similarly, and that (2) people tend to feel more resentment or anger when they think that relevantly similar cases have been treated differently than when they think that relevantly different cases have been treated similarly. Kent Greenawalt argues:

Just as the principle that equals should be treated equally exerts an ethical pull against the reasons for giving unequal treatment to equals, its corollary, the principle that unequals should be treated unequally, exerts some ethical pull against

\footnotetext{
54 Out of habit, a hunter can presume that her gun is loaded and check the chamber before handling the gun even when she remembers well that she left the gun unloaded. This is a valuable practice and it shows that requiring "certainty" can be a reasonable demand in some contexts. Cf. Walton (1988, p. 238).

55 A person's confidence threshold (in particular, acceptance threshold) can be quite high if it is very important for her to avoid believing falsely certain proposition (such as "these cases are relevantly different"). The higher the threshold, the stronger the evidence required to reach it. Cf. Mele (2001, p. 34).
} 
the reasons for giving equal treatment to unequals. This is not necessarily to say that the respective principles are commonly perceived to have the same degree of force. Virtually any administrative program demands rough categorizations that predictably will lead to equal treatment of persons understood to be relevantly unequal in relation to desert or the purposes of the program. Moreover, at least in modern western culture, people usually feel a more acute resentment when those they deem equal are treated better than they are (e.g., given a higher salary) than when those they feel are relevantly less deserving are treated equally (e.g., given the same salary). ${ }^{56}$

These are interesting claims. If they are correct, then we have at least some grounds for preferring equal treatment of relevantly different cases to unequal treatment of relevantly similar cases. No doubt, the reasons Greenawalt mentions concern (1) conventions and (2) the importance of avoiding certain reactions (that people allegedly might have) rather than justice. In that respect, they do not directly show (even if true) that it would be just to prefer equal treatment of relevantly different cases to unequal treatment of relevantly similar cases. Furthermore, many people think that it is equally unjust to treat relevantly different cases similarly rather than to treat relevantly similar cases differently. ${ }^{57}$ However, the claim that there is something particularly bad in treating similar cases differently has some intuitive plausibility (although people's intuitions differ here). Perhaps a case can be made in defense of the thesis that if one must choose between treating unequals equally and treating equals unequally, then she should treat unequals equally.

However, the second question is trickier and more important. Why should the allocator think that it is most important and absolutely necessary to try to avoid the situation in which either the worst possible distribution comes true or equal cases are treated unequally? Consider the following argument. The most important social value is equality. To further social equality one must always avoid all distributive solutions that may lead to social inequalities, understood as situations in which relevantly equal people get unequal share of goods at issue. If the allocator in the painting example gave both paintings to A, the result could be social inequality. Therefore she ought not to give both paintings to A, whatever the prospects of that solution would be. Instead, the allocator should distribute the paintings equally, as it has not been proven that the cases are not similar. That is, the distributive criterion was not decided by free and fair agreement (which is one way to secure that the criterion would be correct), and the empirical data that were used were not sufficiently reliable (as they were based on testimony). It was not indisputably shown that A did everything.

The argument shows that it is possible to defend the justificational interpretation of the presumption of equality against the counter example above. Possibly, in the example, the person should not give both paintings to A-despite the fact that it is very likely that A deserves them both. However, the argument also reveals that the

\footnotetext{
56 Greenawalt (1983, p. 1175).

57 Katzner (1973, p. 92). From the point of view of comparative justice, it is equally unjust to give a bigger share to a person who should get only an equal share than to give a lesser share to a person who should get an equal share. Similarly, from the point of view of noncomparative justice, it is equally unjust to give two paintings to a person who should get only one painting than to leave a person without paintings although she should get one. Cf. Feinberg (1974).
} 
price of the defense of the justificational view is very high. Anyone who would like to rely on it (or on some similar argument) is committed to value choices that must look very extremist for most of us. (At least, they seem very extremist to me.) The justificational view can be saved only by claiming that equality (or the avoidance of the worst possible distribution) is such an important value that we are justified and indeed obligated to make choices that are very likely to lead to evident injustice. That kind of extremism does not sound correct, although some people-namely the extremists-may find it acceptable.

The lesson is that the justificational view is an implausible guide for just decisionmaking. ${ }^{58}$ Unless the allocator is willing to accept some sort of extremism, she should not rely on the presumption of equality if she has good reason to assume that the cases are different, whether or not she is able to justify her views in a surefire way. It seems that the presumption of equality can be justifiably applied much less often than its supporters tend to think. A person who gives a good justification for her claim can meet the burden of proof even if she has not given an indisputable justification for that claim.

\section{Concluding remarks}

I have argued that the presumption of equality is a plausible principle in circumstances when a person is at a loss how to make the distribution. But I have also argued that it is a mistake to think that when a person is ignorant only in the sense that she does not have a justification for the claim that the cases are different, she should rely on the presumption of equality. The view that the differential treatment requires a full justification of the claim that the cases are different can be defended only by relying on implausible extremism.

I have emphasized that refuting the presumption of equality and showing that the cases are different are two separate matters. A person can have good enough reasons for rejecting the presumption that the cases are relevantly similar without having reasons that she could present as a full justification for the claim that the cases are relevantly different. I have not tried to define how strong reasons suffice to refute the presumption of equality. In particular, I have not defended the claim that the standard of proof should be low. I have only argued that the standard should not be as high as the justificational view suggests. Unequal distribution can be acceptable even when the arguments in favor of it do not meet the most demanding standards. However, my argument does not have any "conservative" implications, that is, the argument does not imply that meeting the burden should be somehow easy. Even if we do not accept the justificational view it may turn out that the rejection of the presumption of equality is often a demanding task.

Since the presumption of equality can be refuted without full justification of the claim that the cases are different, disagreements about the true acceptability of the differential treatment cannot be decided by considering whether the burden of proof

\footnotetext{
58 To give "some" justification for the claim that the cases are different is not to give a "proper" or "full" justification for that claim. When a person gives "some" justification for the claim, she will meet the burden of proof. But this does not mean that she has given a (proper) justification for that claim.
} 
has been met. A person who has sufficient reasons for the rejection of the presumption that that the cases are similar need not have reasons that are morally right and justify the differential treatment. We could say that when a person has reasons that justify the rejection of the presumption, she has met the original burden of proof. However, those who disagree with her can argue that her reasons are actually wrong, and if they manage to present sufficiently good objections, they have met the evidential burden of proof. To meet the evidential burden of proof is to show that the argument that refuted the original burden of proof needs further support. ${ }^{59}$

The question of "what sorts of reasons are acceptable as grounds for differential treatment" $" 60$ is ambiguous and has two different meanings. The person who asks it may be interested in knowing what sorts of reasons can refute the presumption of equality, or she may be interested in knowing what sorts of reasons suffice to justify the claim that the cases are relevantly different. It has been assumed far too often that a single reply could answer these two separate questions.

Acknowledgements Open access funding provided by University of Turku (UTU) including Turku University Central Hospital. I would like to thank Joseph Almog, Anna-Karin Andersson, Polaris Koi, Mireille Musangamfura, Andrei Rodin, Jukka Varelius and the Editors and the anonymous referees for helpful comments.

Open Access This article is distributed under the terms of the Creative Commons Attribution 4.0 International License (http://creativecommons.org/licenses/by/4.0/), which permits unrestricted use, distribution, and reproduction in any medium, provided you give appropriate credit to the original author(s) and the source, provide a link to the Creative Commons license, and indicate if changes were made.

\section{References}

Adler, J. E. (2002). Belief's own ethics. London: The MIT Press.

Benn, S. I. (1967). Equality, moral and social. In P. Edwards (Ed.), The encyclopedia of philosophy (pp. 38-41). New York: Macmillan.

Benn, S. I., \& Peters, R. S. (1959). The principles of political thought. New York: Macmillan.

Berlin, I. (1955-1956). Equality. Proceedings of the Aristotelian Society, NS 56, 301-326.

Bohman, J., \& Richardson, H. S. (2009). Liberalism, deliberative democracy, and "reasons that all can accept". The Journal of Political Philosophy, 17, 253-274.

Browne, D. E. (1975). The presumption of equality. Australasian Journal of Philosophy, 53, 46-53.

Cauthen, K. (1987). The passion for equality. Totowa: Rowman \& Littlefield.

Dixon, K. (1986). Freedom and equality. London: Routledge.

Feinberg, J. (1973). Social philosophy. Englewood Cliffs: Prentice-Hall.

Feinberg, J. (1974). Noncomparative justice. Philosophical Review, 83, 297-338.

Fogelin, R., \& Sinnott-Armstrong, W. (1991). Understanding arguments. Fort Worth: Harcourt Brace Jovanovich Publishers.

Foley, R. (2001). Intellectual trust in oneself and others. Cambridge: Cambridge University Press.

Frankena, W. K. (1966). Some beliefs about justice. Kansas: University of Kansas.

Gosepath, S. (2007). Equality. Stanford Encyclopedia of Philosophy. Internet source.

Gosepath, S. (2008). The presumption of equality. In Myung-Hyun-Lee (Ed.), Proceedings of the XXII World Congress of Philosophy (pp. 205-211). Philosophy Documentation Center.

Gosepath, S. (2015). The principles and the presumption of equality. In C. Fourie, F. Schuppert, \& I. Wallimann-Helmer (Eds.), Social equality: On what it means to be equals (pp. 167-185). Oxford: Oxford University Press.

59 Cf. Rescher (1977, p. 27).

60 Rees (1971, p. 133). 
Graham, A. C. (1965). Liberty and Equality. Mind, 74, 59-65.

Greenawalt, K. (1983). How empty is the idea of equality? Columbia Law Review, 83, 1167-1185.

Guerro, A. A. (2017). Living with ignorance in a world of experts. In R. Peels (Ed.), Perspectives on ignorance from moral and social philosophy (pp. 156-185). New York: Routledge.

Hare, R. M. (1963). Freedom and reason. Oxford: Clarendon Press.

Katzner, L. I. (1970-1971). Presumptivist and Nonpresumptivist Principles of Formal Justice. Ethics, 81, 253-258.

Katzner, L. I. (1973). Presumptions of reason and presumptions of justice. The Journal of Philosophy, 70, 89-100.

Lackey, J. (2011). Acquiring knowledge from others. In A. I. Goldman \& D. Whitcomb (Eds.), Social epistemology: Essential readings (pp. 71-91). Oxford: Oxford University Press.

Lehrer, K. (2006). Testimony and trustworthiness. In J. Lackey \& E. Sosa (Eds.), The epistemology of testimony (pp. 145-159). Oxford: Clarendon Press.

Mele, A. R. (2001). Self-deception unmasked. Princeton: Princeton University Press.

Miller, D. (1997). Equality and justice. Ratio (ns), 10, 222-237.

Norman, R. (1987). Free and equal. Oxford: Oxford University Press.

Peels, R. (2010). What is ignorance? Philosophia, 38, 57-67.

Rabinowicz, W. (2008). Presumption of equality. Lund Philosophy Reports, 1, 109-155.

Rabinowicz, W. (2011). Presumption of equality as a requirement of fairness. In E. N. Dzhafarov \& L. Perry (Eds.), Descriptive and normative approaches to human behavior (pp. 203-224). Singapore: World Scientific Publishing.

Räikkä, J. (2014). Social justice in practice: Questions in ethics and political philosophy. Heidelberg: Springer.

Räikkä, J. (2018). On the presumption of equality. The Critical Review of International Social and Political Philosophy. https://doi.org/10.1080/13698230.2018.1438335.

Rees, J. (1971). Equality. London: Pall Mall.

Rescher, N. (1977). Dialectics. Albany: State University of New York Press.

Rosen, G. (2003). Culpability and ignorance. Proceedings of the Aristotelian Society, 103, 61-84.

Smith, H. M. (2010). The "prospective view" of obligation. Journal of Ethics \& Social Philosophy, 5, 1-8. Ullmann-Margalit, E. (1983). On presumption. The Journal of Philosophy, 80, 143-163.

Walton, D. N. (1988). Burden of proof. Argumentation, 2, 233-254.

Walton, D. N. (1996). Arguments from ignorance. University Park: The Pennsylvania State University Press. Westen, P. (1990). Speaking of equality. Princeton: Princeton University Press.

Zimmerman, M. J. (1997). Moral responsibility and ignorance. Ethics, 107, 410-426.

Zimmerman, M. J. (2008). Living with uncertainty: The moral significance of ignorance. Cambridge: Cambridge University Press.

Zimmerman, M. J. (2014). Ignorance and moral obligation. Oxford: Oxford University Press.

Publisher's Note Springer Nature remains neutral with regard to jurisdictional claims in published maps and institutional affiliations. 